\title{
Two sets of initial conditions on boreal forest carbon storage economics
}

\author{
Petri P. Kärenlampi* \\ Lehtoi Research, Finland \\ petri.karenlampi@professori.fi \\ * Author to whom correspondence should be addressed.
}

\begin{abstract}
Two sets of initial conditions are used in the investigation of capital return rate and carbon storage in boreal forests. Firstly, a growth model is applied in young stands as early as the inventory-based model is applicable. Secondly, the growth model is applied to observed wooded stands. Four sets of thinning schedules are investigated in either case. First, the capital return rate is aspired without any restriction. Second, the number of thinnings is restricted to at most one. Third, thinnings are restricted to the removal of only trees thicker than $237 \mathrm{~mm}$. Fourth, commercial thinnings are omitted. The two sets of initial conditions yield similar results. The capital return rate is a weak function of rotation age, which results in variability in the optimal number of thinnings. Reducing the number of thinnings to one increases timber stock but induces a capital return rate deficiency. The deficiency per excess volume unit is smaller if the severity of any thinning is restricted by the removal of large trees only. Omission of thinnings best applies to spruce-dominated stands with stem count less than 2000/ha. Restricted thinning intensity applies to deciduous stands and dense pine stands. The albedo effect increases the benefits of restricted thinnings and increased clearcuttings instead of contradicting the carbon storage.
\end{abstract}

Keywords: capital return rate deficiency; expected value; carbon storage; carbon rent; albedo effect

\section{Introduction}

There are two large sinks of atmospheric carbon on planet Earth: the oceans and the forests $[1,2,3,4]$. It is difficult to manipulate oceans, whereas forests can be managed. By definition, a carbon sink is a system with a positive time change rate of stored carbon. This paper discusses the microeconomics of boreal forests as a carbon sink.

A particular benefit of the boreal forest is carbon storage in the soil; the amount of soil carbon may exceed the carbon storage in living biomass $[5,6,7,8,9,10]$. However, living biomass produces the litter resulting in soil carbon accumulation, and consequently, the rate of carbon storage depends on the rate of biomass production on the site. The biomass production rate is related to the amount of living biomass $[6,11,9,12]$. As the time change rate of storage constitutes a sink, this paper focuses on changes in living biomass. In the case of trees, one of the most straightforward indicators of living biomass per surface area unit is the commercial volume of tree trunks.

The outcome of any process depends on the essential contributing mechanisms. Such mechanisms can often be described in terms of a process model. However, the outcome also depends on the occurring initial conditions, or more broadly, boundary conditions. In real-life 
applications, the initial conditions vary. Results of model-based investigations can be considered robust (or non-chaotic) if they are coherent under realistically varying sets of initial conditions [13].

This paper investigates carbon storage in boreal forests using a growth model based on large inventory datasets [14]. To gain possibly robust results, two different sets of initial conditions are used. Both of the sets of initial conditions have been described in recent investigations $[15,16,17]$, but have not been applied simultaneously in the clarification of any single problem.

The process model, together with the initial conditions, could produce an outcome. However, in this paper, there are more elements. There are objective functions. The objective functions are partially microeconomic, partially of a physical character. The microeconomic objective function is the capital return rate $[18,19,20,16,17]$. The physical objective functions are carbon storage area densities, discussed in terms of living biomass, and measured in area densities of commercial trunk volumes.

There is a hierarchy between the objective functions. Firstly, the capital return rate is maximized. Then, deviations are introduced, and the relationship of capital return rate deficiency to excess commercial volume is investigated. The deviations are introduced in terms of four additional sets of boundary conditions. These are constituted by four sets of restrictions applied to intermediate harvesting practices, or, in other words, thinning restrictions. Some of the restrictions may result in a favorable combination of carbon storage and capital return deficiency, in which case the deficiency could be compensated in terms of a carbon rent [21].

\section{Materials and methods}

The two different sets of initial conditions have been described in three earlier investigations $[15,16,17]$. Firstly, a group of nine setups was created, containing three tree species and three initial sapling densities [17]. The idea was to apply the inventory-based growth model as early in stand development as it is applicable, to avoid approximations of stand development not grounded on the inventory-based growth model [14]. This approach also allowed an investigation of a wide range of stand densities, as well as a comprehensive description of the application of three tree species. The exact initial conditions here equal the ones recommended in [17], appearing there in Figures 8 and 9.

The second set of initial conditions is here reported in more detail. The tree species distribution was not accounted for in previous publications [15, 16]. Within the seven wooded, commercially unthinned sample plots of age from 30 to 45 years, located in Eastern Finland, the total stem count varied from 1655 to 2451 per hectare. A visual quality approximation was implemented. The number of stems deemed suitable for growing further varied from 1050 to 1687 per hectare. The distribution of the basal area (cross-sectional area of all trees at breast height) of these acceptable-quality trees into tree species is shown in Fig. 1; the basal area of the acceptable-quality trees varied from 28 to $40 \mathrm{~m}^{2} / \mathrm{ha}$, in all cases dominated by spruce (Picea abies) trees. 


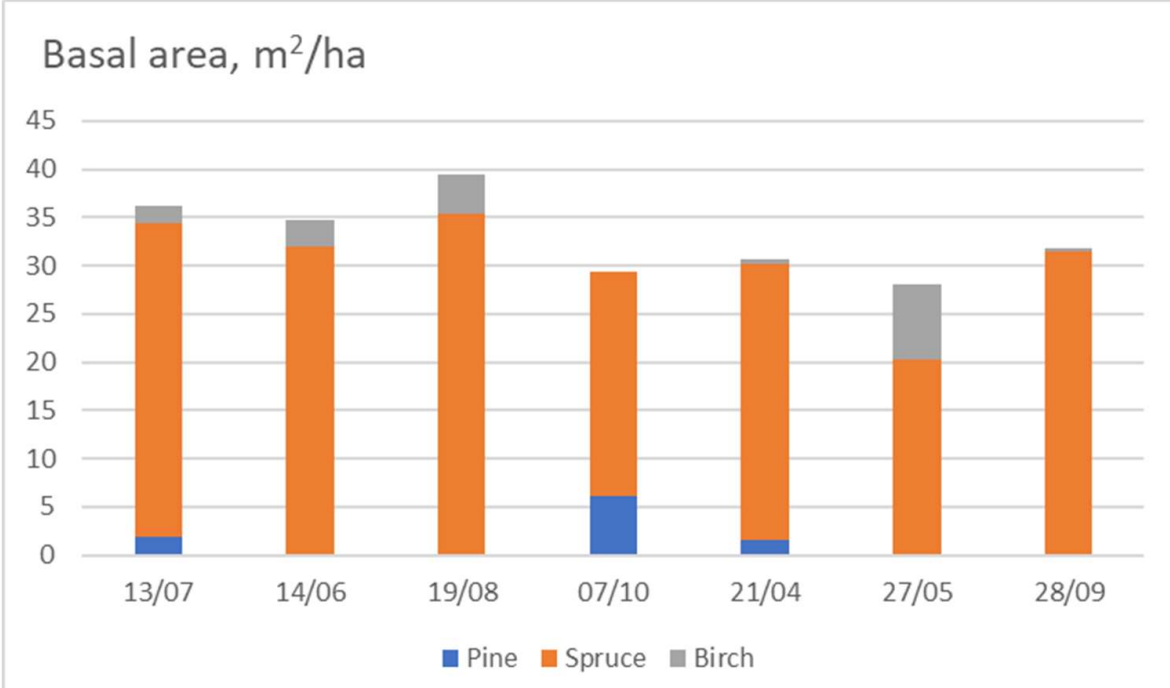

Figure 1. Distribution of basal area of acceptable-quality trees into tree species at seven sample plots.

The growth model - the process model acting on the initial conditions - used in this study has been established in 2008 by Bollandsås et al. [14], based on a comprehensive forest inventory in Norway. The growth model has been applied in a variety of earlier investigations $[15,22$, 17]. In this study, it is used exactly in the same form as in [17].

To clarify the capital return rate, a financial treatment is needed. We apply a procedure first mentioned in the literature in 1967 , but applied only recently [23,24,18, 19,20,16,17]. Instead of discounting revenues, the capital return rate achieved as relative value increment at different stages of forest stand development is weighed by current capitalization, and integrated. The procedure applies to forest estates of any distribution of site properties, but the result is stationary in time only if the stand age distribution within the forest estate is even. Assumption of even age distribution of stands within an estate corresponds to the "normal forest principle" [25], where any established stand setup or observed sample plot serves as a "normal stand" of an estate $[19,20,16,17]$. Regeneration expenses are capitalized at the time of regeneration and amortized at the end of any rotation [17].

Finally, as the initial conditions and the growth process function have been established, as well as the objective function as the expected value of capital return rate, four sets of operative boundary conditions are applied. First, intermediate harvesting events (thinnings) are designed for any normal stand to maximize the capital return rate, without any restriction. Second, the number of thinnings is restricted to one. Third, the severity of any thinning is restricted by removing large trees only. A breast-height diameter limit of $238 \mathrm{~mm}$ is used. The fourth boundary condition consists of the omission of commercial thinnings.

The three latter of the four boundary conditions defined above in general result as a deficient capital return rate, in comparison to the first (with no restriction). However, at the expense of a capital return deficiency, the magnitude of carbon storage may be increased. 


\section{Results}

Fig. 2 shows that in the case of pure spruce stands (Fig 2a), the capital return rate is maximized by one, two, or three thinnings, depending on the initial seedling density [17]. Increased seedling density increases the number of thinnings, as well as rotation time, regardless of the tree species (Fig. 2a). Silvicultural practices giving the greatest capital return rate correspond to a rotation age of 89 years. However, the capital return rate, especially in the case of high seedling densities, is a weak function of the rotation age, and correspondingly, a reduction in the number of thinnings (Fig 2b) would change the capital return rate only moderately. Restricting thinnings to the removal of trees thicker than $237 \mathrm{~mm}$ would result in only two of the nine data series (setups) being thinned (Fig. 2c). Omission of thinnings reduces rotation times significantly but capital return rates only moderately (Fig. 2d). There is a significant difference between tree species, which however does not differ much between the applied thinning restrictions.

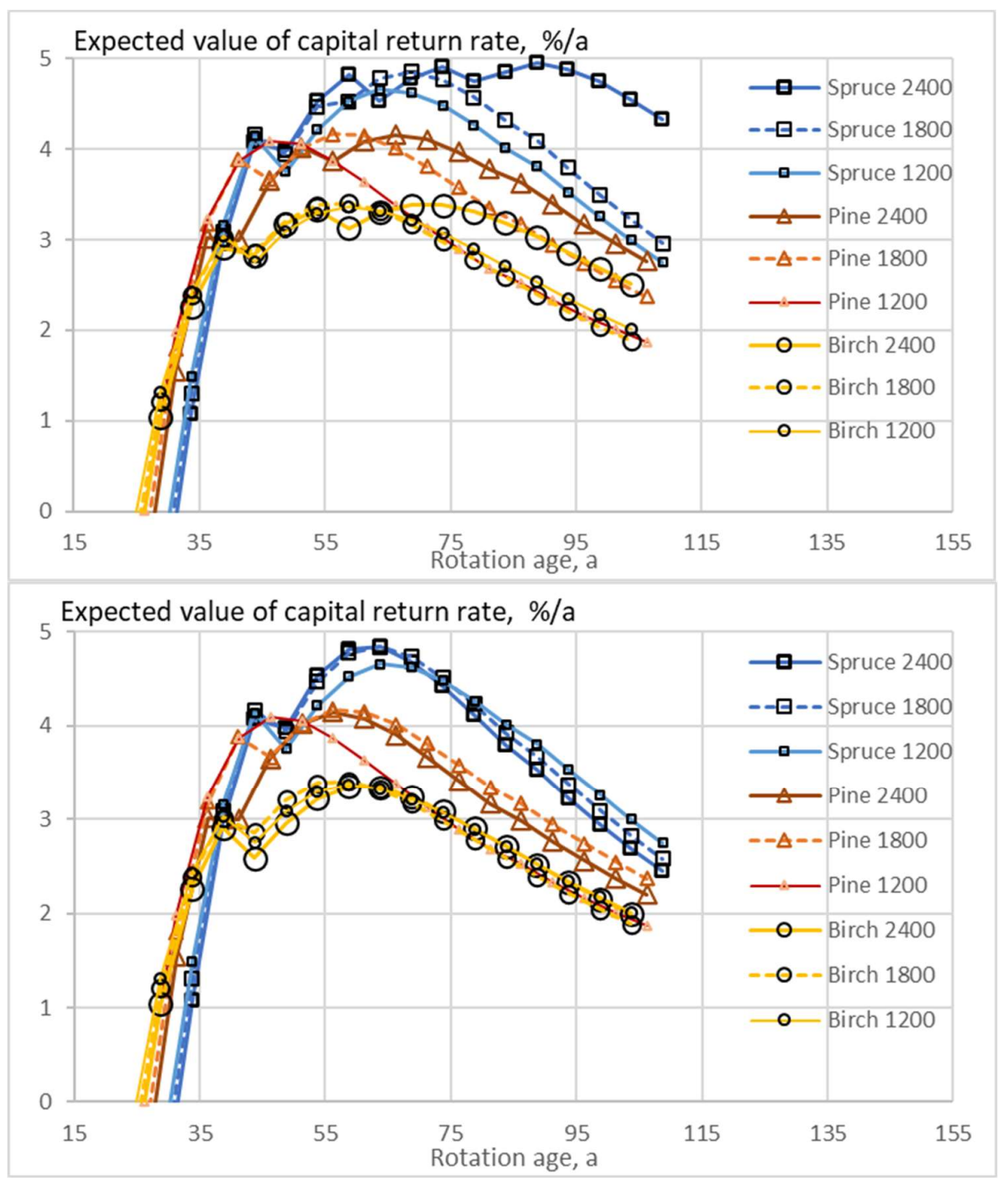



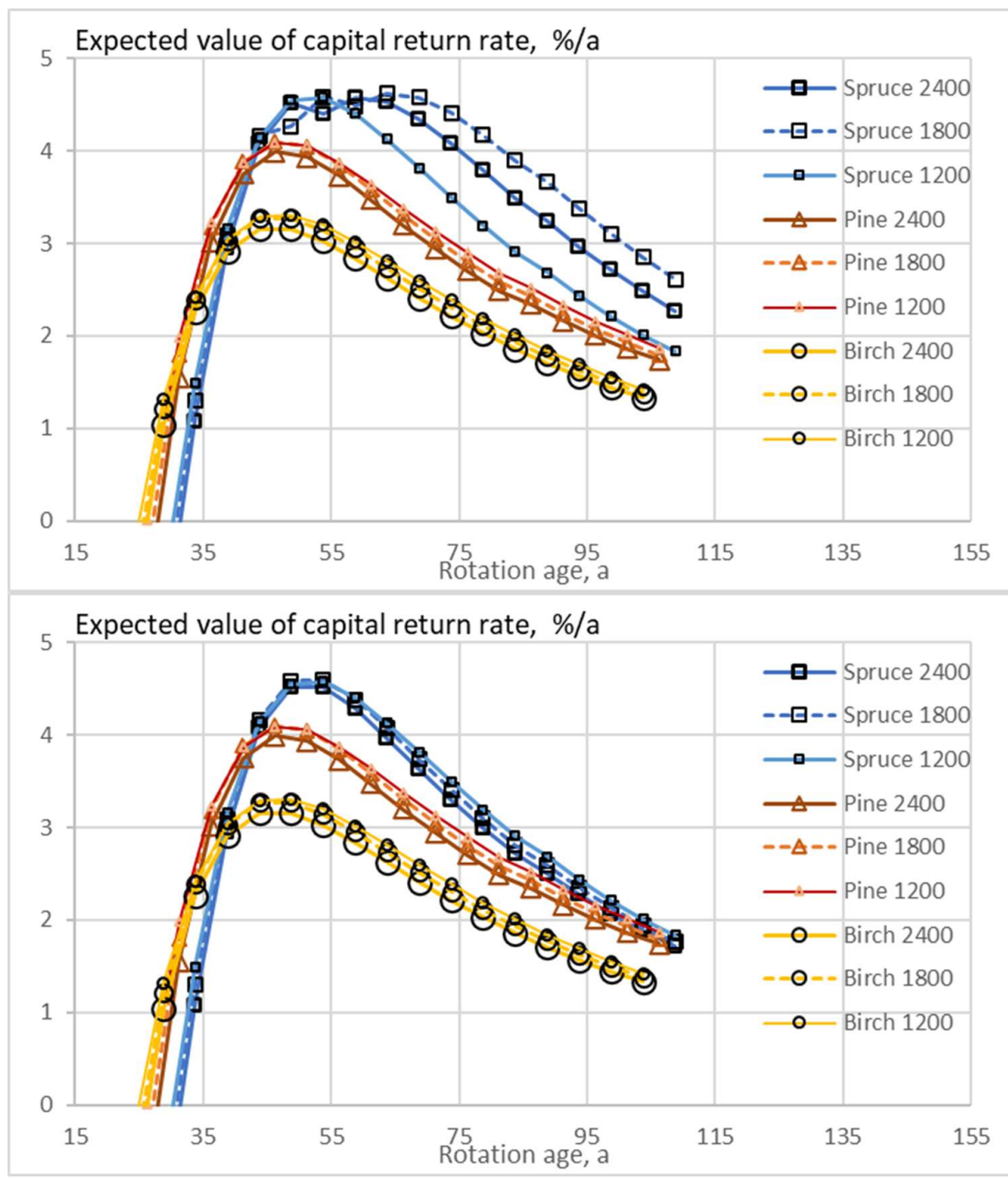

Figure 2. The expected value of capital return rate, as a function of rotation age, when growth model is applied as early as possible. (a) no restrictions on thinning treatments (b) number of thinnings restricted to at most one (c) thinning restricted to removal of trees thicker than 237 mm (d) thinnings omitted.

The seven wooded normal stands (Fig 3) somewhat differ in terms of the number of thinnings. In five normal stands, the greatest capital return rate is gained with one thinning, whereas two thinnings are required in the remaining two cases (Fig. 3a). Optimal rotation ages are 62, 50, $50,80,77,53$, and 53 years. On the other hand, there is some resemblance to Fig. 2a. In the case of stands thinned more than once, the capital return rate is a weak function of rotation age (Fig. 3a). The same would happen in the case of stands thinned only once if additional thinnings would be introduced.

Restricting the number of commercial thinnings to one (Fig. 3b) naturally would affect only the two normal stands where two thinnings would take place according to Fig. 3a. Restricting thinnings to the removal of trees thicker than $237 \mathrm{~mm}$ would induce one thinning in five normal stands and two in two normal stands (Fig. 3c), always reducing the rotation time in relation to Fig. 3a. Omission of thinnings further reduces rotation times but reduces capital return rate only moderately (Fig. 3d). 

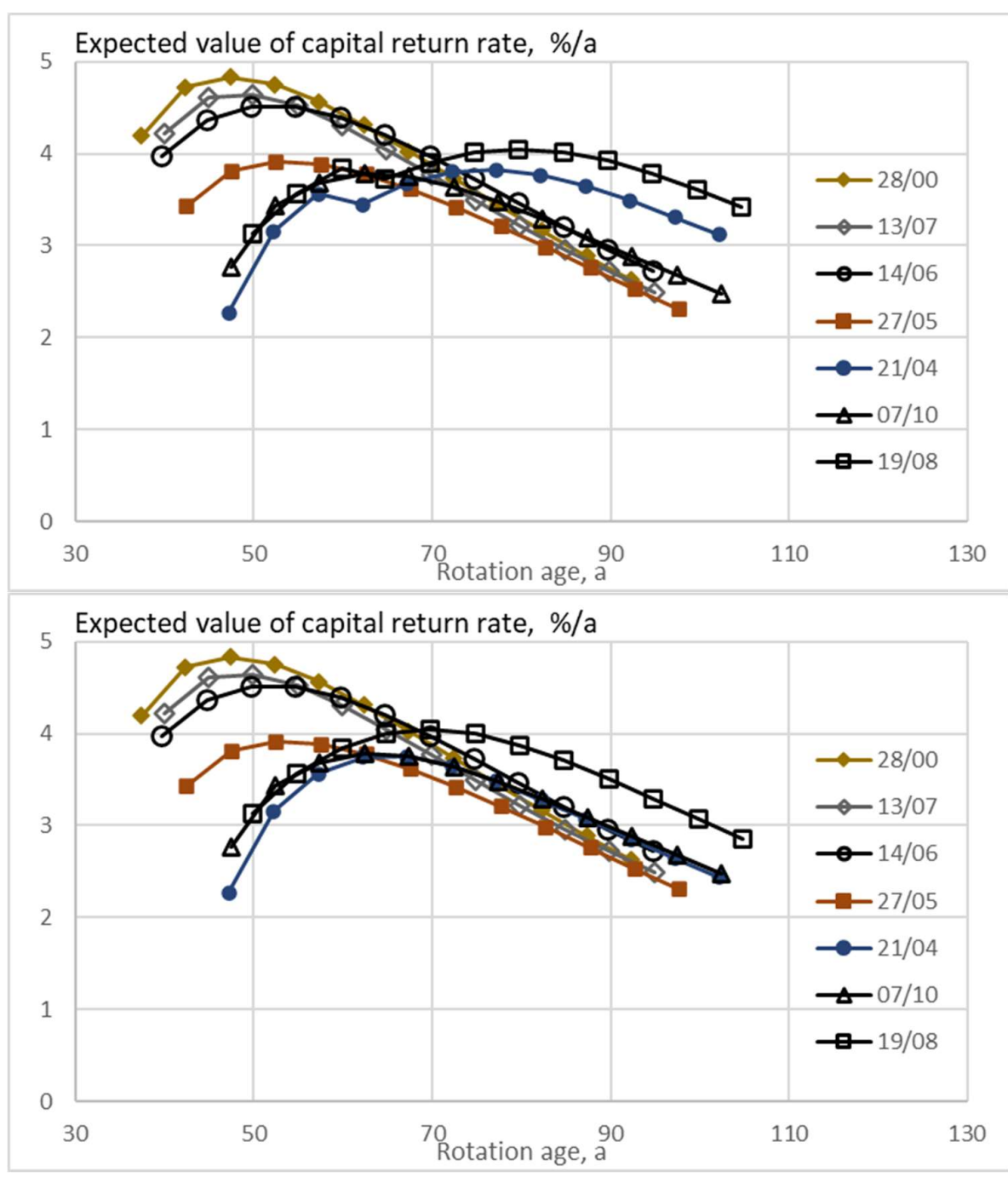

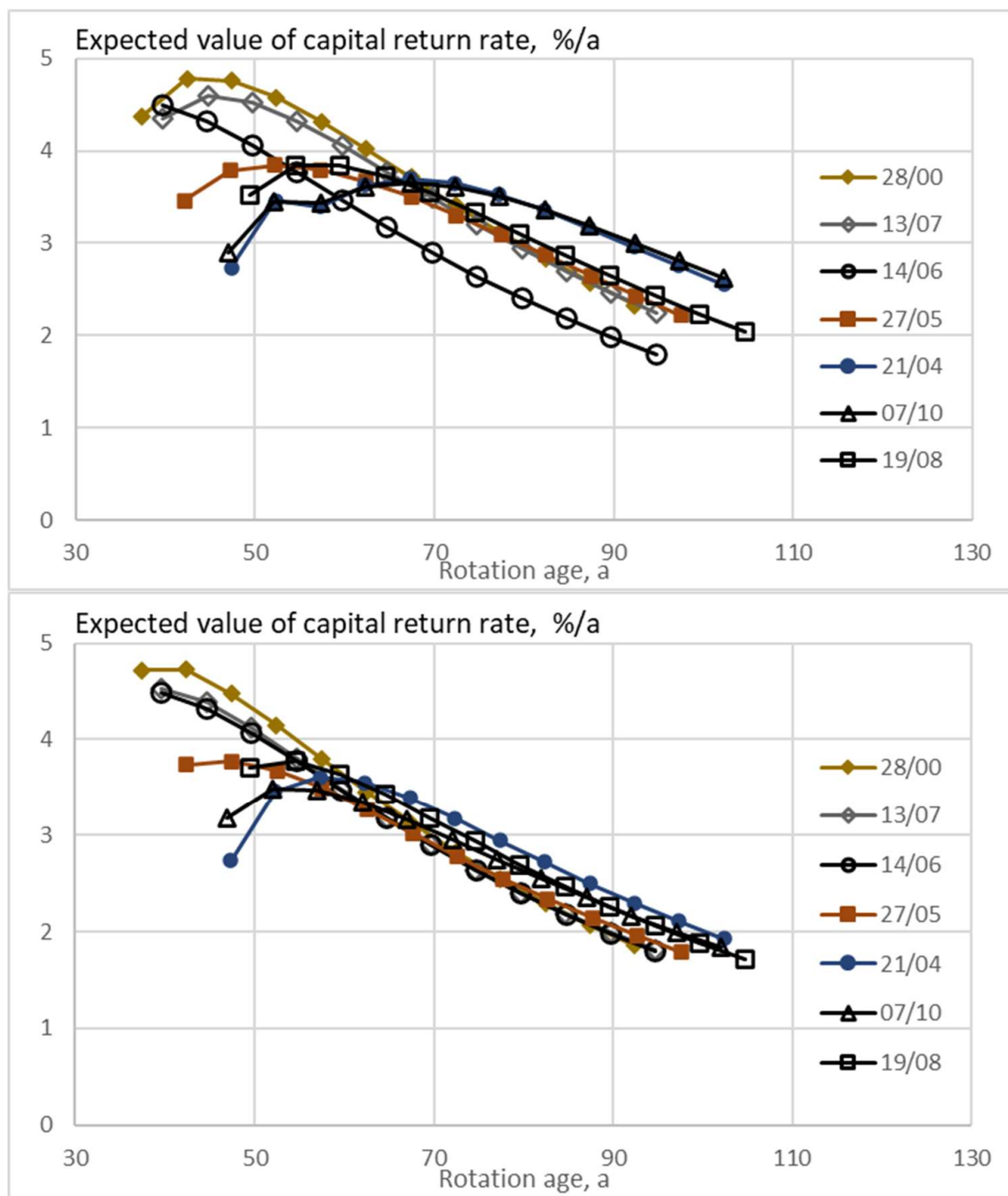

Figure 3. The expected value of capital return rate, as a function of rotation age, when the growth model is applied to observed wooded stands. (a) no restrictions on thinning treatments (b) number of thinnings restricted to at most one (c) thinning restricted to trees thicker than 237 mm (d) thinnings omitted.

Any deviation from the procedures corresponding to the maximum capital return rate induces a deficiency in capital return rate. Annual monetary deficiency per hectare can be gained by multiplying the deficiency in percentage per annum by current capitalization per hectare.

Any deviation from the procedures corresponding to the maximum capital return rate also changes the expected value of the volume of trees per hectare. In case the volume is greater than that volume corresponding to the maximum capital return rate, there is a positive expected excess volume (also a negative excess volume may appear). The annual monetary deficiency per hectare can be divided by the excess volume to yield a measure of the financial burden of increasing the timber stock.

Silvicultural practices giving the greatest capital return rate in Fig. 2a correspond to an expected value of stand volume of $139 \mathrm{~m}^{3} /$ ha. This is achieved with a relatively long rotation time of 89 years. Figure 4 shows the capital return rate deficiency per excess volume unit as a function of 
positive excess volume. It is found that without any restriction to thinning practices, possibilities for increasing timber storage are limited (Fig. 4a). Restricting the number of thinnings to at most one provides much higher excess volumes with a lower expense (Fig. 4b). Restricting thinnings to the removal of trees thicker than $237 \mathrm{~mm}$ would further increase achievable excess volumes and reduce the corresponding capital return deficiencies (Fig. 4c). This restriction results in only two of the nine data series becoming thinned (Figs. 1c, 4c). Omitting all thinnings after young stand tending still increases achievable excess volumes and also reduces the corresponding capital return deficiencies (Fig. 4d). However, at moderate excess volumes, the lowest capital return deficiencies in the case of the spruce stand with high initial stem count are gained by restricting thinnings to the removal of trees thicker than 237 mm (Figs. 4c and 4d).

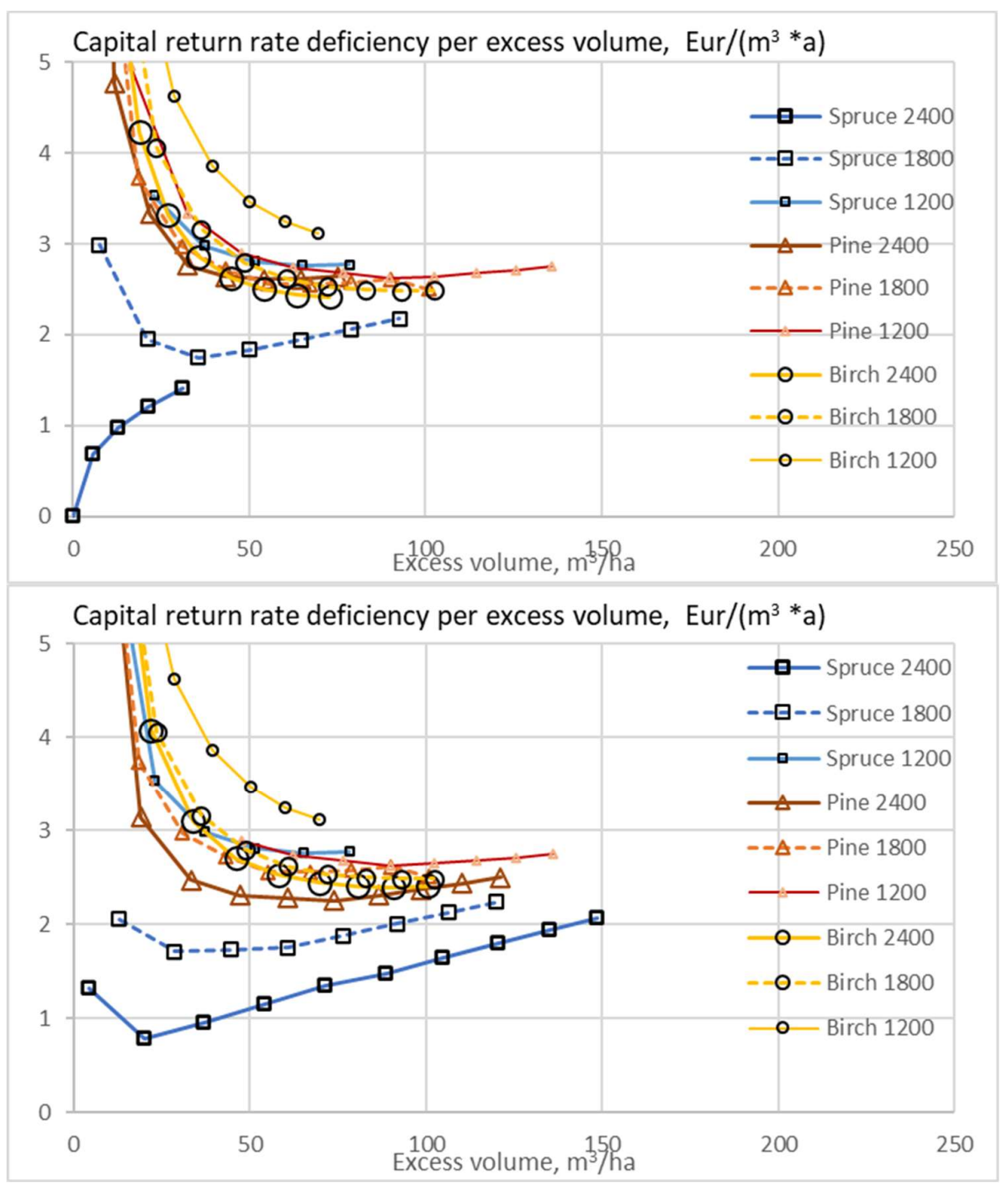




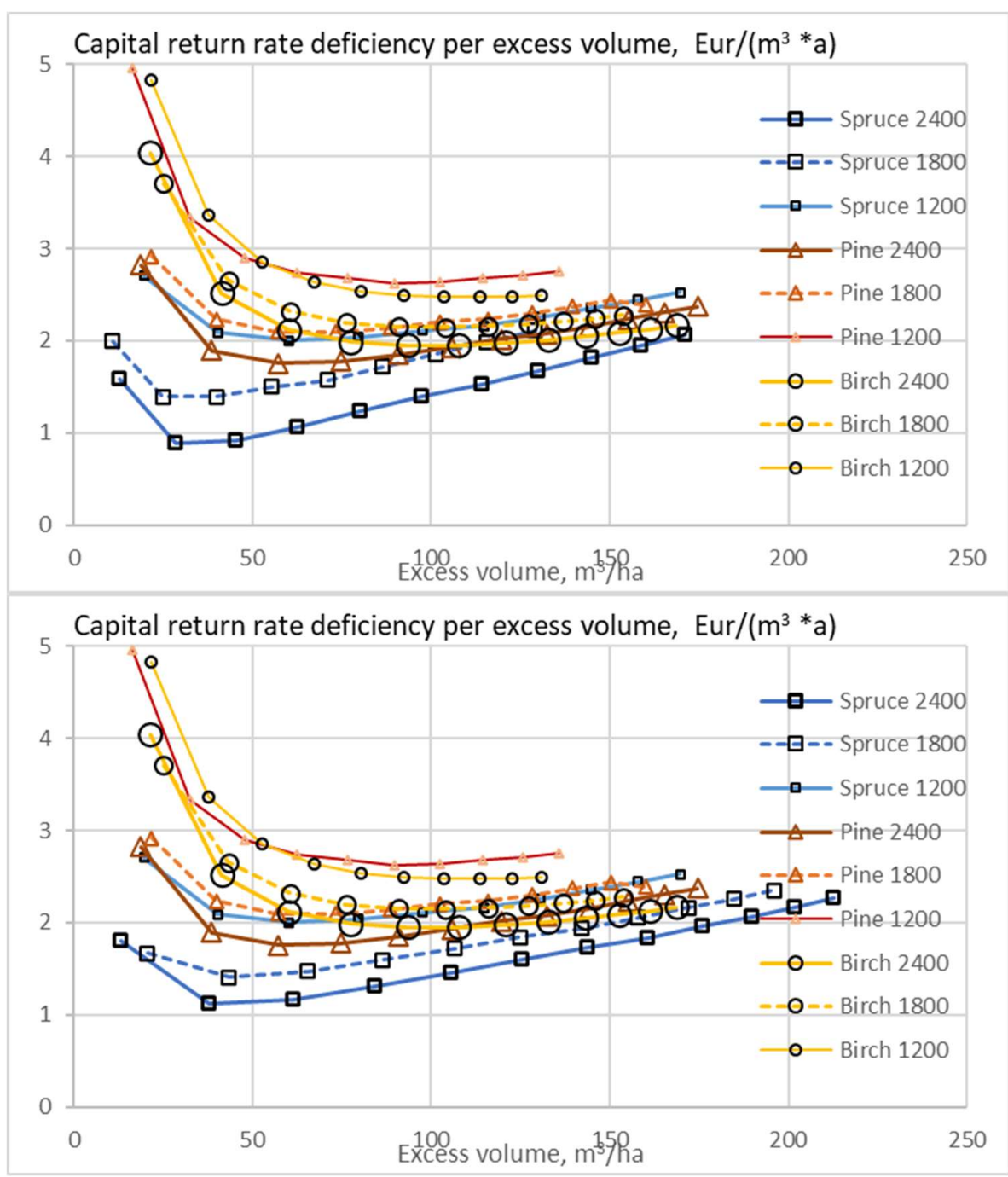

Figure 4. Capital return rate deficiency per excess volume unit, as a function of excess volume, when the growth model is applied as early as possible. (a) no restrictions on thinning treatments (b) number of thinnings restricted to at most one (c) thinning restricted to trees thicker than 237 $\mathrm{mm}(\mathrm{d})$ thinnings omitted.

In Fig. 4, the capital return rate deficiency, as well as the excess volume were shown in comparison to the stand setup providing the best available capital return rate. However, there are three alternative tree species and three seedling densities investigated. Any of these nine setups is likely have dynamics of its own. Fig. 5 shows the setup-specific capital return rate deficiency per excess volume, as a function of setup-specific excess volume. We find from Fig. 5a that within any setup, excess volume can be gained by extending rotation time, with a moderate capital return rate deficiency. However, in the case of spruce cultivation with the highest initial seedling density, the achievable excess volume is not large (Fig. 5a). Restricting the number of thinnings to one increases the available excess volume within a few setups. In the case of the spruce stand with the highest initial stem count, the capital return rate deficiency is reduced (Fig. 5b). Restricting thinnings to the removal of trees thicker than $237 \mathrm{~mm}$ further increases achievable excess volume and decreases the corresponding capital return rate deficiency in all cases (Fig. 5c). Omission of thinnings in Fig. 5d changes the situation in the case of the two setups that would experience thinning in Fig. 5c: available excess volume increases, and capital return rate deficiency per excess volume is reduced. 


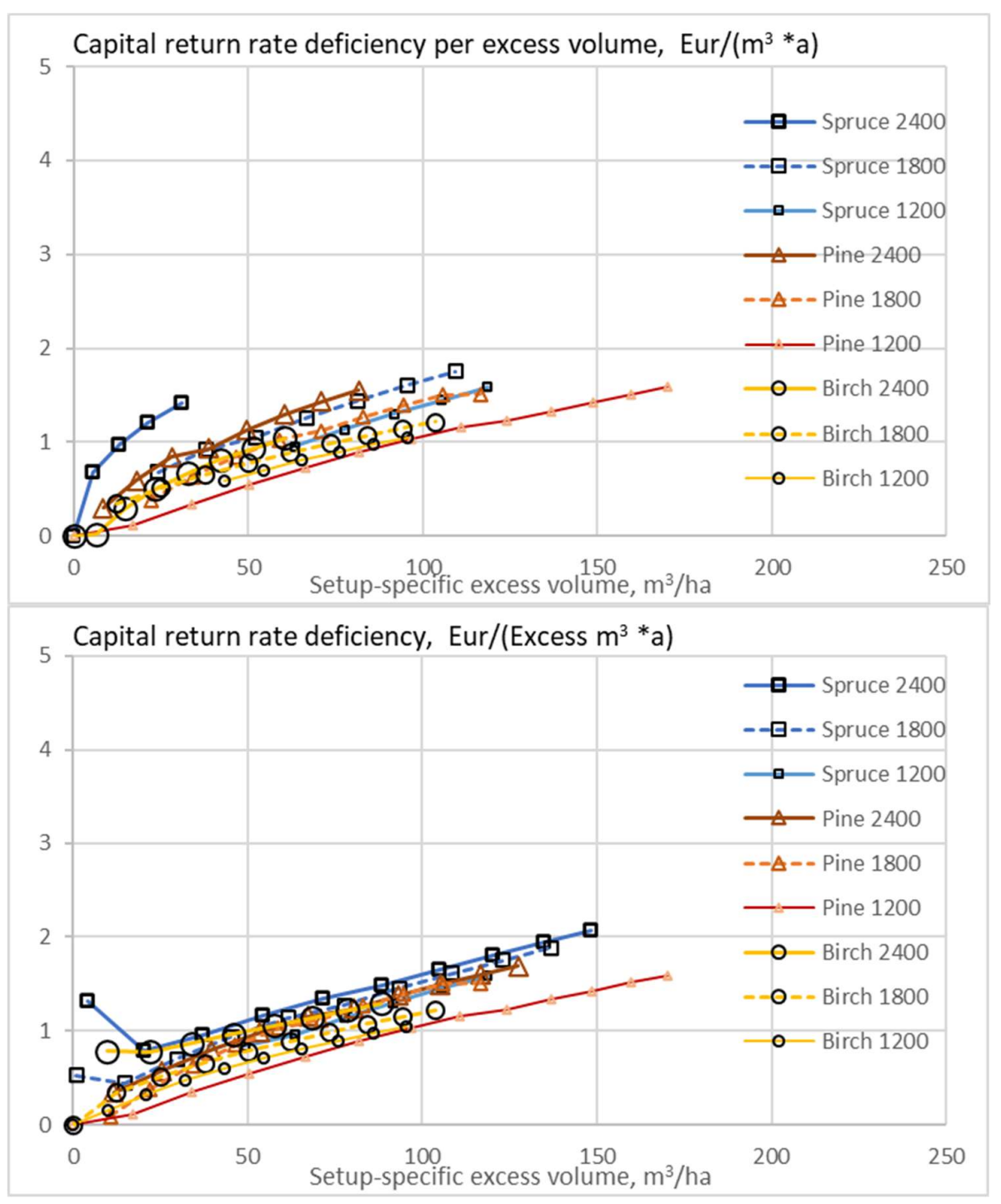




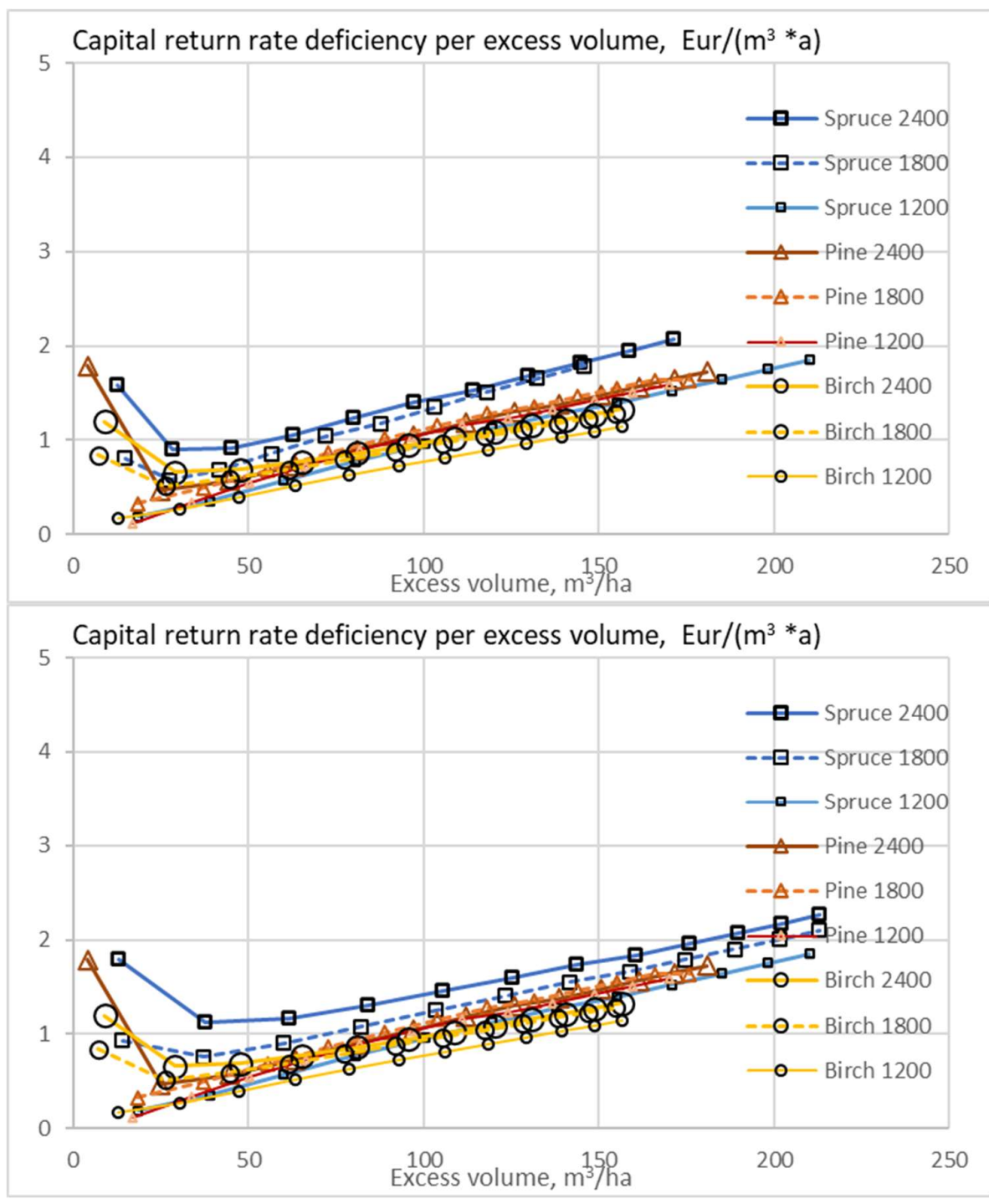

Figure 5. Setup-specific capital return rate deficiency per excess volume unit, as a function of setup-specific excess volume, when growth model is applied as early as possible. (a) no restrictions on thinning treatments (b) number of thinnings restricted to at most one (c) thinning restricted to trees thicker than $237 \mathrm{~mm}$ (d) thinnings omitted.

The expected values of stand volumes corresponding to the maximum capital return rate in the case of the seven wooded stands used as normal stands (Fig 3) are 104, 117, 102, 111, 120, 103 , and $104 \mathrm{~m}^{3} /$ ha. Figure 6 shows capital return rate deficiency per excess volume as a function of excess volume for these seven cases. We find from Fig. $6 a$ that within any case, excess volume can be gained by extending rotation time, with a moderate capital return rate deficiency. Restricting the number of thinnings to one (Fig. 6b) increases the available excess volume within those normal stands thinned twice in Fig. 6a (cf. Fig. 2a). Restricting thinnings to the removal of trees thicker than $237 \mathrm{~mm}$ increases achievable excess volume and decreases the corresponding capital return rate deficiency in all cases (Fig. 6c). Omission of thinnings in Fig. $6 \mathrm{~d}$ increases available excess volumes and further reduces corresponding capital return rate deficiencies per excess volume unit. 

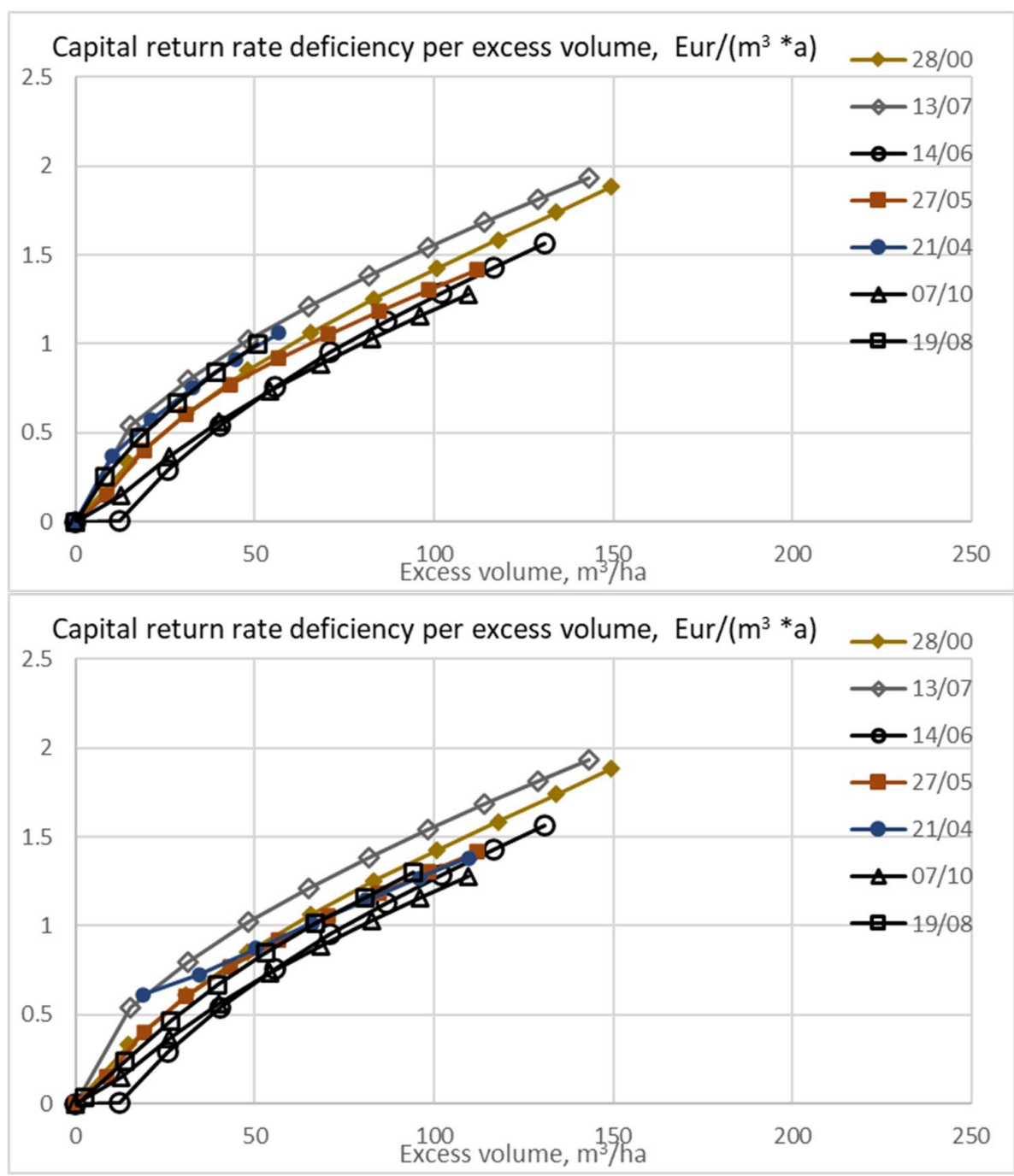


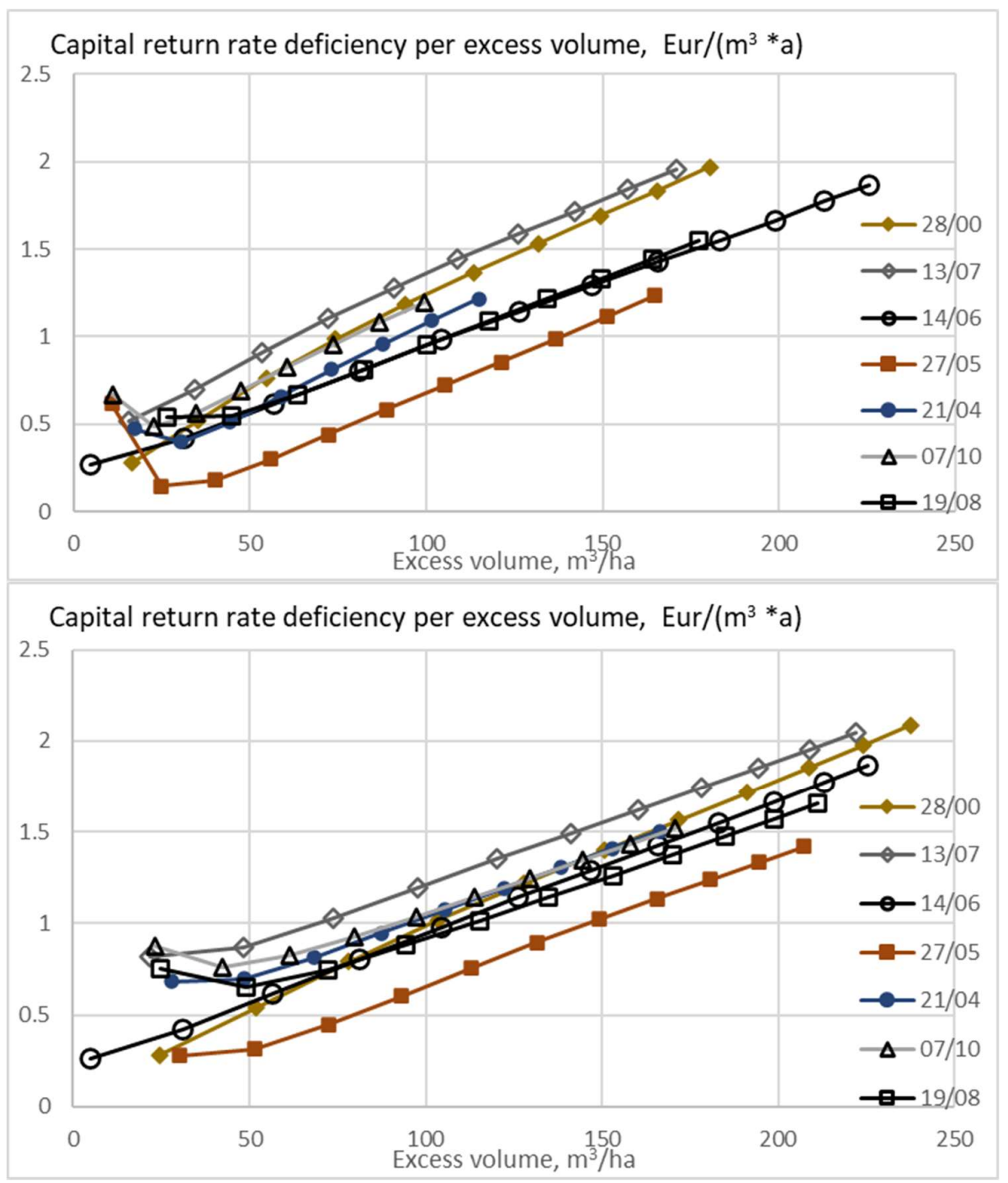

Figure 6. Capital return rate deficiency per excess volume unit, as a function of excess volume, when the growth model is applied to observed wooded stands. (a) no restrictions on thinning treatments (b) number of thinnings restricted to at most one (c) thinning restricted to trees thicker than $237 \mathrm{~mm}$ (d) thinnings omitted.

\section{Discussion}

It appears that restriction or omission of thinnings is a cost-effective way of enhancing carbon sequestration in boreal forestry. Implementation of thinnings is microeconomically profitable, but a moderate carbon rent would motivate to omit thinnings and consequently sequester carbon. Within the boreal region, omission of thinnings would make most productive forest sites unthinned within 40 years. If this would increase carbon storage by $40 \%$, the annual increment would be in the order of $1 \%$ of the present carbon stock. This would correspond to at least a ton of $\mathrm{CO}_{2}$ per hectare, or at least 10 million tons for 10 million hectares, as additional sequestration due to omission of thinnings. At the global 2018 emission level, the additional sequestration would compensate for the emissions induced by two million humans, or about one million in developed countries [26,27]. It is worth noting that these tonnage estimates are minimum estimates; an increment of necromass and soil carbon level may further increase the 
additional amount of sequestration due to omission of thinnings [5,6,7,8,9,10,]. The corresponding expense, in terms of carbon rent, would be very small (in the order of one Euro per hectare) in the beginning and increase about 40 times during the sequestration process [21].

It is of interest to compare the $40 \%$ carbon storage increment achievable by restriction or omission of thinnings to carbon storage increments achievable by other means. One opportunity obviously would be fertilization. Fertilization increases growth of coniferous boreal forests [34,35], but it is economically profitable in the case of stands where most of the additional growth rapidly increases sawlog yield. Let us first write the expected value of commercial stand volume per hectare

$$
\langle V\rangle=\frac{1}{\tau} \int_{0}^{\tau} V(t) d t
$$

Let us then write the momentary volume as the sum of volume in the absence of fertilization and additional volume due to fertilization:

$$
\langle V\rangle=\frac{1}{\tau} \int_{0}^{\tau}\left(V_{0}(t)+\Delta V(t)\right) d t
$$

Now, the relative increment of the expected value of volume due to fertilization is

$$
\frac{\langle V\rangle}{\left\langle V_{0}\right\rangle}=1+\frac{\int_{0}^{\tau} \Delta V(t) d t}{\int_{0}^{\tau} V(t) d t}
$$

On the right-hand side of Eq. (3), the numerator of the second term is in the order of 50-100 $\mathrm{m}^{3} /$ ha. However, the denominator is in the order of $5000-10000 \mathrm{~m}^{3} / \mathrm{ha}$. Correspondingly, the increment of the expected value of commercial volume is in the order of $1 \%$, corresponding to an excess volume of $1-2 \mathrm{~m}^{3} / \mathrm{h}$. The situation would change if the fertilization would happen decades before final harvesting. However, even if fertilization would happen 20 years before harvest, the numerator would be in the order of $200 \mathrm{~m}^{3} / \mathrm{ha}$, and the expected value of volume increment in the order of $3 \%$.

A question arises, whether there are adverse effects for the society or the economy. How would restricted thinnings affect the wood supply of forest-based industries?

The wood supply question primarily concerns how restricted thinnings contribute to the production rate of wood raw materials. This can be clarified since the growth model [14] yields the expected values of the net growth rate of commercial timber. Fig. 7 shows the relative growth rate as a function of excess volume for the nine combinations of tree species and seedling density, the growth model applied as early as it is applicable. The expected value of the net growth rate is given in relation to the growth rate corresponding to the maximal capital return rate within any setup.

Fig. 7a shows that simply extending rotation times increases the growth rate in the case of spruce stands and pine stands of low seedling density. It reduces the growth rate in the case of birch stands and dense pine stands. The effects are the same when the number of thinnings is restricted to one, except for a clearer growth increment in dense spruce stands (Fig. 7b). Restricting thinnings to the removal of trees thicker than $237 \mathrm{~mm}$ amplifies not only the excess 
volume but also the growth rate increments (Fig. 7c). Omission of thinnings, however, reverses the growth rate increment in the case of dense spruce stands (Fig. 7d).

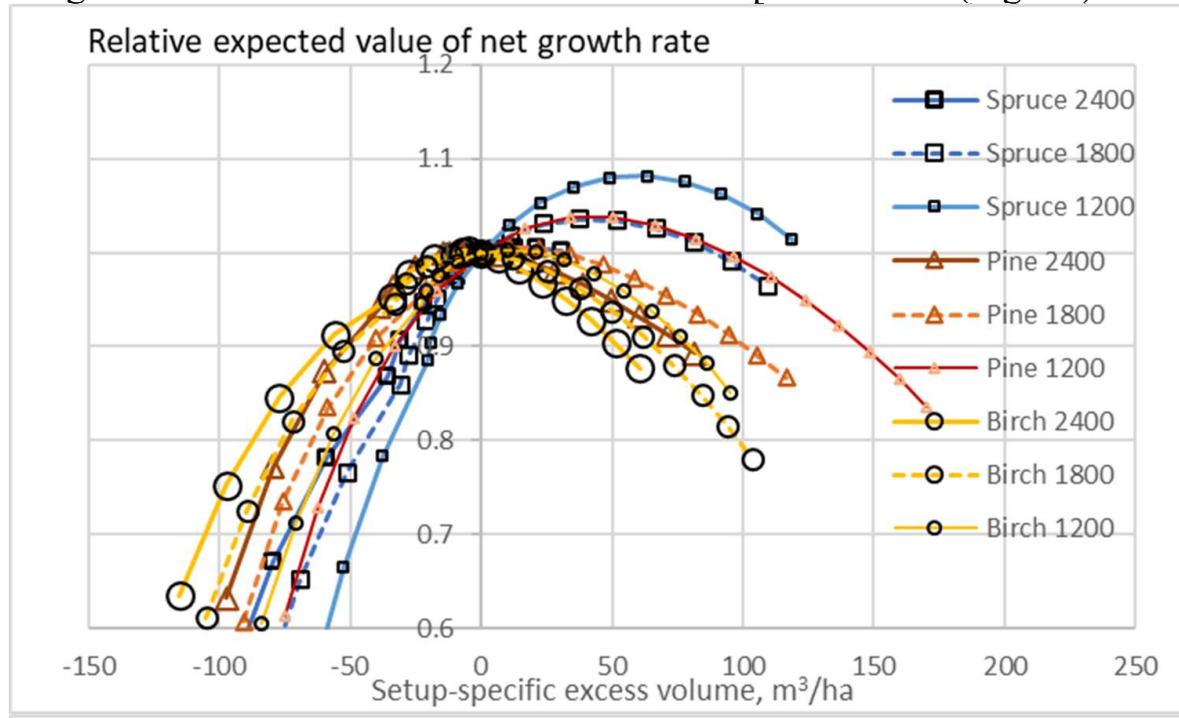

Relative expected value of net growth rate

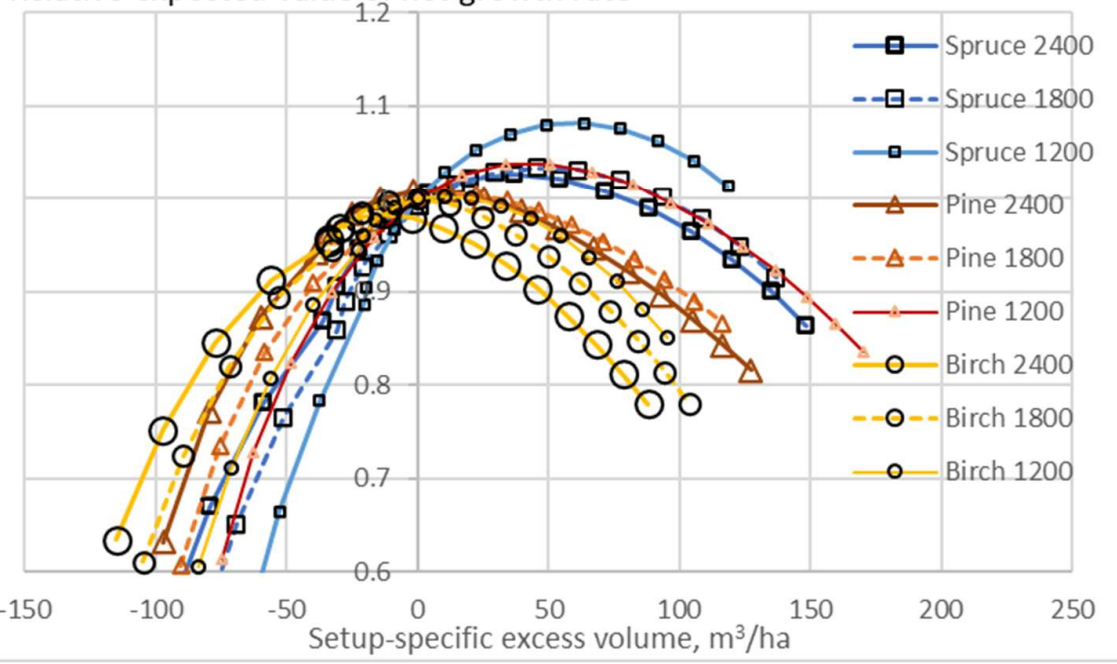




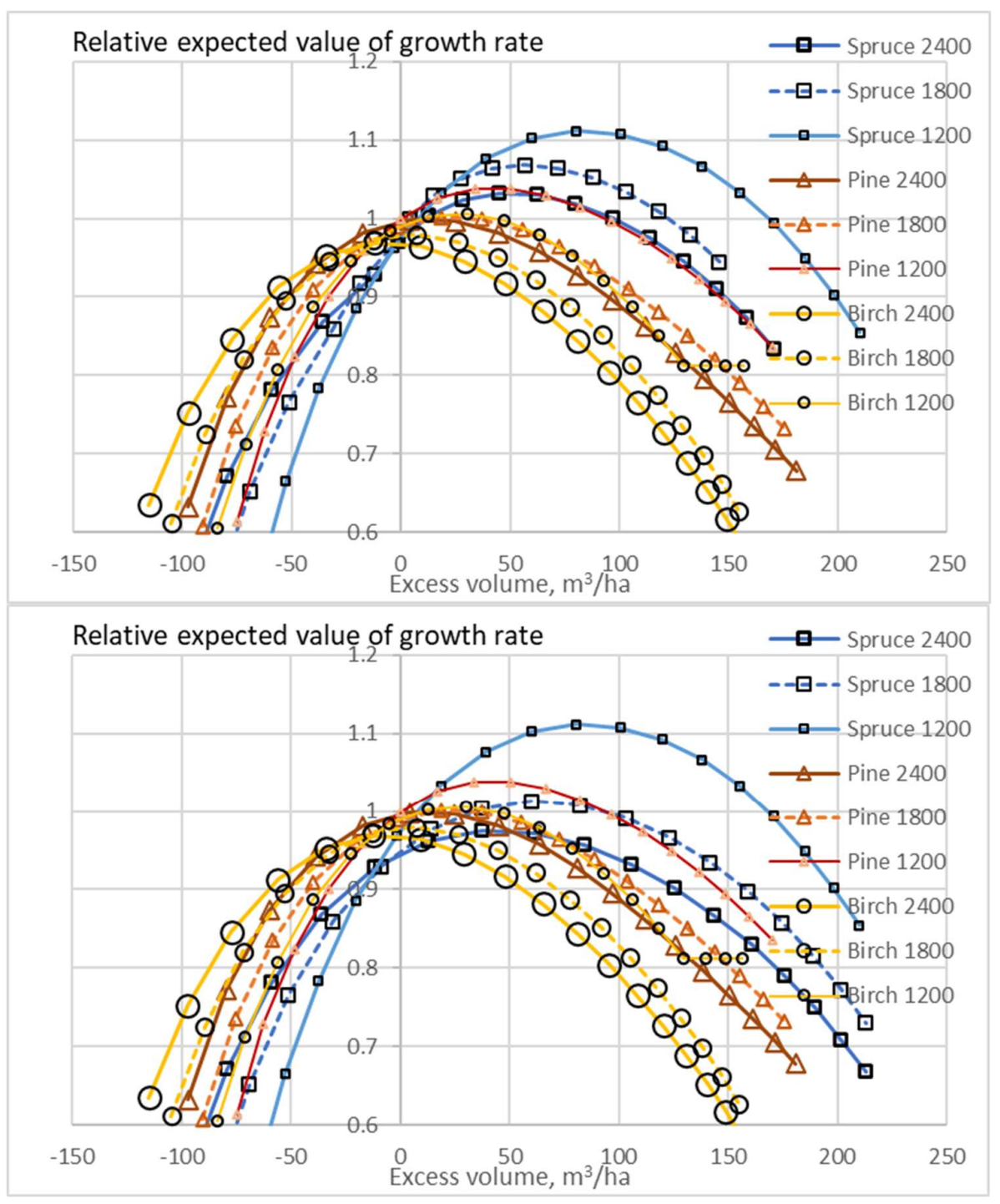

Figure 7. Setup-specific expected value of relative annual growth rate, as a function of setupspecific excess volume, when growth model is applied as early as possible. The growth rate is given in relation to the growth rate appearing when the capital return rate is maximized without restrictions (co-ordinate $(0,1)$ in Fig. 7a). (a) no restrictions on thinning treatments (b) number of thinnings restricted to at most one (c) thinning restricted to trees thicker than $237 \mathrm{~mm}(\mathrm{~d})$ thinnings omitted.

The seven observed wooded normal stands show slight or moderate increments in growth rate when the rotation age is increased (Fig. 8a)). Reduction of the number of thinnings to one induces almost the same (Fig. 8b). Restricting thinnings to the removal of trees thicker than $237 \mathrm{~mm}$, combined with a moderate excess volume, increases the growth rate in all cases (Fig. $8 \mathrm{c})$. Omission of thinnings, with a moderate excess volume, leaves the growth rate unaffected in two cases and increases it in five cases (Fig. 8d).

One can summarize that restricting or omitting thinnings for carbon sequestration increases the supply of commercial timber in spruce-dominated forest, as well as in pine forests of low stem count (Figs. 7 and 8). In birch forests, as well as on dense pine stands, the net growth of commercial timber is reduced. 

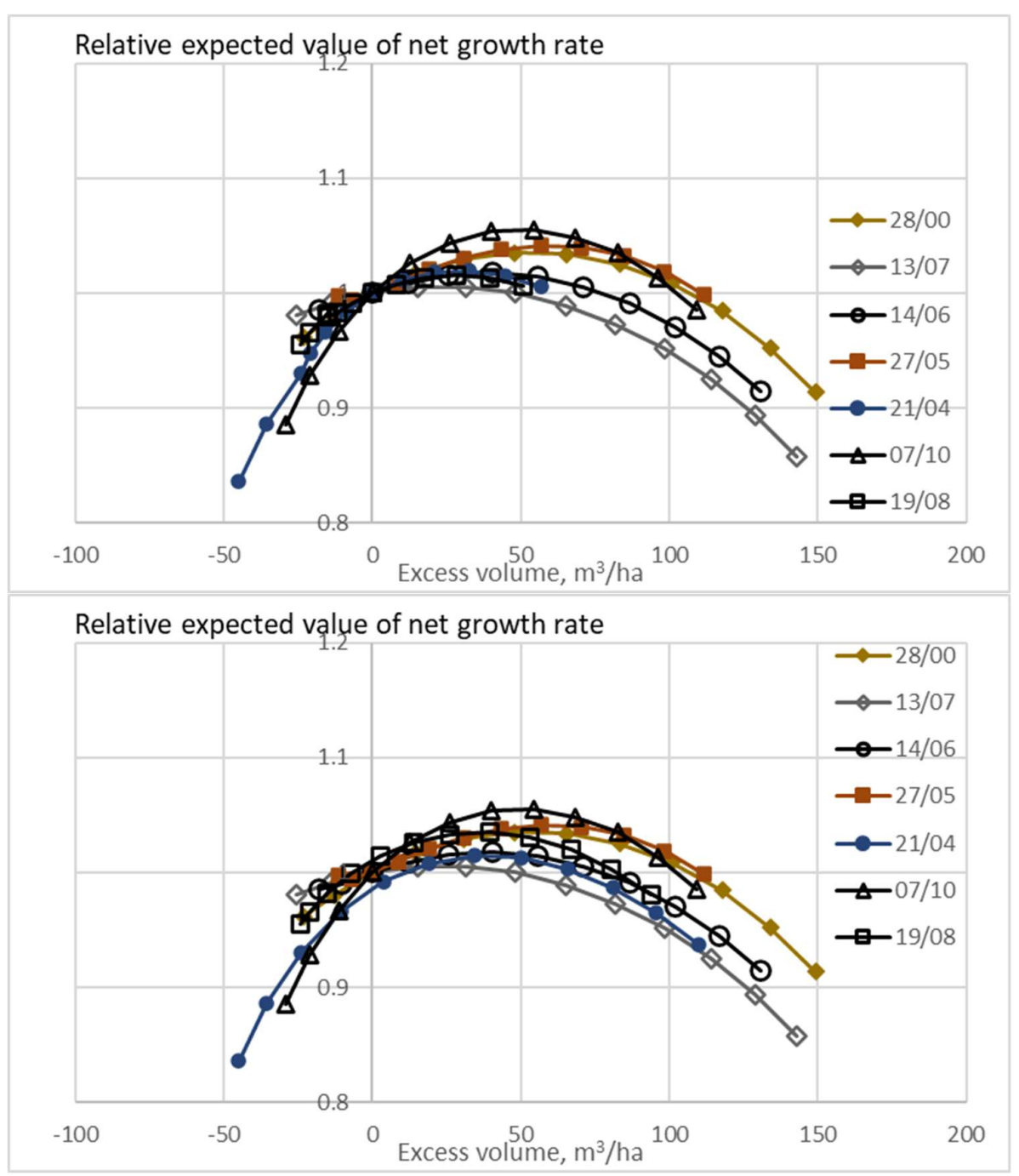


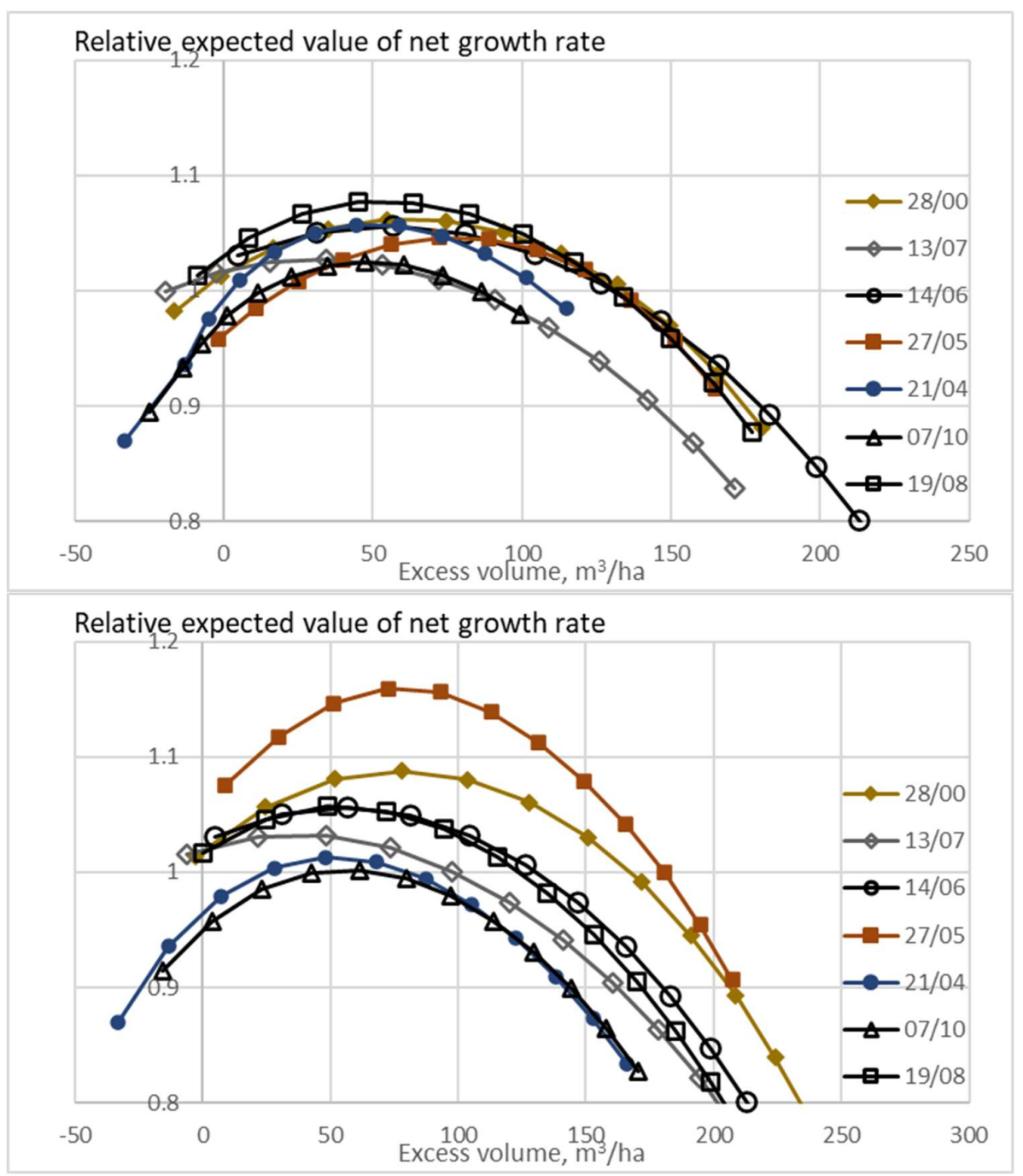

Figure 8. The expected value of relative annual growth rate, as a function of excess volume, when growth model is applied to observed wooded stands. The growth rate is given in relation to the growth rate appearing when the capital return rate is maximized without restrictions (coordinate $(0,1)$ in Fig. 8a). (a) no restrictions on thinning treatments (b) number of thinnings restricted to at most one (c) thinning restricted to trees thicker than $237 \mathrm{~mm}$ (d) thinnings omitted.

Another question is, how the omission of thinnings contributes to different wood-based industries. Within southern and central boreal regions, thinnings mostly yield pulpwood, while clearcuttings yield sawlogs and plywood logs [28]. The proportion of sawlogs and plywood logs appears as $35-40 \%$ of the total yield [28]. An unknown proportion of the sawlogs is used in pulping, instead of sawmilling. Omission of commercial thinnings directly reduces the supply of pulpwood but increases the pulpwood content in clearcuttings. However, the growth model applied in this study indicates that the total sawlog yield does not collapse, but rather is retained [17]. This requires that young stand tending and eventual precommercial thinning are properly implemented, leaving at most 2000 stems per hectare [17].

Restriction or omission of thinnings significantly reduces harvesting expenses [29]. 
Eventual adverse effects of the omission of thinnings do not solely depend on the growth rate. Practical macroscopic consequences depend on macroscopic boundary conditions. As such, increment of timber stock might periodically reduce wood supply, while increased growth (in spruce-dominated forests) would increase it in longer term. However, present timber stocks may exceed microeconomically optimal levels [28]. In such a case, a carbon storage compensation would prohibit an expected timber stock reduction in the future, again increasing wood supply in the long term.

It is worth noting that while the omission of thinnings reduces rotation times (Figs. 2 and 3), age-related risks are likely to be reduced. Omission of thinnings naturally reduces thinningsrelated risks like wind damage $[30,31,32,33]$.

Last but not least, restriction or omission of thinnings and the corresponding reduction of rotation times increases the area proportion of areas not covered by dense vegetation. This increases the albedo effect: radiation is reflected from open surfaces [36,37,38,39,40,41]. A portion of the reflected radiation is able to exit the atmosphere [36,39]. Some results indicate deciduous forests would reflect more than coniferous [37,38]. The albedo effect apparently is of somewhat smaller magnitude than the variation due to carbon sequestration, but greater than the substitution effect of fossil fuel emissions by biomass [36,39]. Several earlier studies have claimed the albedo effect counteracts carbon storage ambitions; carbon storage would require longer rotation times, whereas albedo enhancement would benefit from a greater proportion of open areas $[38,39,42]$. This paper indicates the contrary: restricted thinnings are related to reduced rotation times (Figs. 2 and 3), which again relates to positive albedo effects.

The operative outcome of this paper is possibly affected by the albedo consideration in the selection of tree species. In Figs. 4c and 4d, deciduous stands show a greater capital return rate deficiency per excess volume unit than coniferous stands. Correspondingly, they require a higher carbon rent. However, a greater carbon rent may be justified by the greater albedo effect $[37,38]$.

\section{Acknowledgement}

This work was partially funded by Niemi foundation.

\section{References}

1. https://ocean-climate.org/en/awareness/the-ocean-a-carbon-sink/ Accessed Jul 17, 2021.

2. Hauck, J.; Zeising, M.; Le Quéré, C.; Gruber, N.; Bakker, D.C.E.; Bopp, L.; Chau, T.T.T.; Gürses Ö.; Ilyina T.; Landschützer P.; Lenton A.; Resplandy L.; Rödenbeck C.; Schwinger J.; Séférian R. Consistency and Challenges in the Ocean Carbon Sink Estimate for the Global Carbon Budget. Frontiers in Marine Science 7, 2020, 852.

3. Friedel, M. Forests as Carbon Sinks. https://www.americanforests.org/blog/forests-carbonsinks/ Accessed Jul 17, 2021.

4. Goodale, C.L.; Apps, M.J.; Birdsey, R.A.; Field, C.B.; Heath, L.S.; Houghton, R.A.; Jenkins, J.C.; Kohlmaier, G.H.; Kurz, W.; Liu, S.; Nabuurs, G.; Nilsson, S.; Shvidenko, A.Z. FOREST CARBON SINKS IN THE NORTHERN HEMISPHERE. Ecological Applications, 12, 2002, 891-899.

5. Adams, A.; Harrison, R.; Sletten, R.; Strahm, B.; Turnblom, E.; Jensen, C. Nitrogenfertilization impacts on carbon sequestration and flux in managed coastal Douglas-fir stands of 
the Pacific Northwest. For. Ecol. Manag. 2005, 220, 313-325, doi:10.1016/j.foreco.2005.08.018.

6. Lal, R. Forest soils and carbon sequestration. For. Ecol. Manag. 2005, 220, 242-258, doi:10.1016/j.foreco.2005.08.015.

7. Liski, J.; Lehtonen, A.; Palosuo, T.; Peltoniemi, M.; Eggersa, T.; Muukkonen, P.; Mäkipää, R. Carbon accumulation in Finland's forests 1922-2004-an estimate obtained by combination of forest inventory data with modelling of biomass, litter and soil. Ann. For. Sci. 2006, 63, 687-697.

8. Peltoniemi, M.; Mäkipää, R.; Liski, J.; Tamminen, P. Changes in soil carbon with stand age - an evaluation of a modelling method with empirical data. Glob. Chang. Biol. 2004, 10, 2078 2091.

9. Powers, M.; Kolka, R.; Palik, B. J.; McDonald, R.; Jurgensen, M. Long-term management impacts on carbon storage in Lake States forests. For. Ecol. Manag. 2011, 262, 424-431, doi:10.1016/j.foreco.2011.04.008.

10. Riikilä, M. Avohakkuu ei hävitä hiilivarastoa. Metsälehti 21/2020. https://www.metsalehti.fi/artikkelit/avohakkuu-ei-havita-hiilivarastoa/\#928d2873 Accessed Jul 17, 2021.

11. Campioli, M.; Vicca, S.; Luyssaert, S.; Bilcke, J.; Ceschia, E.; Iii, F.S.C.; Ciais, P.; Fernández-Martínez, M.; Malhi, Y.; Obersteiner, M.; et al. Biomass production efficiency controlled by management in temperate and boreal ecosystems. Nat. Geosci. 2015, 8, 843-846, doi:10.1038/ngeo2553.

12. Thornley, J.H.M.; Cannell, M.G.R. Managing forests for wood yield and carbon storage: a theoretical study. Tree Physiol. 2000, 20, 477-484, doi:10.1093/treephys/20.7.477.

13. Weisstein, E. Chaos. Wolfram web resources. https://mathworld.wolfram.com/Chaos.html Accessed Jul 17, 2021.

14. Bollandsås, O.M.; Buongiorno, J.; Gobakken, T. Predicting the growth of stands of trees of mixed species and size: A matrix model for Norway. Scand. J. For. Res. 2008, 23, 167-178, doi:10.1080/02827580801995315.

15. Kärenlampi, P.P. Harvesting Design by Capital Return. Forests 2019, 10, 283, doi:10.3390/f10030283.

16. Kärenlampi, P.P. Diversity of Carbon Storage Economics in Fertile Boreal Spruce (Picea Abies) Estates. Sustainability 2021, 13, 560. https://www.mdpi.com/2071-1050/13/2/560

17. Kärenlampi P.P. Capital return rate and carbon storage on forest estates of three boreal tree species. Sustainability 2021, 13(12), 6675; https://doi.org/10.3390/su13126675

18. Kärenlampi, P.P. State-space approach to capital return in nonlinear growth processes. Agric. Finance Rev. 2019, 79, 508-518, doi:10.1108/afr-07-2018-0055.

19. Kärenlampi, P.P. Estate-Level Economics of Carbon Storage and Sequestration. Forests 2020, 11(6), 643; https://doi.org/10.3390/f11060643.

20. Kärenlampi, P.P. The Effect of Empirical Log Yield Observations on Carbon Storage Economics. Forests 2020, 11, 1312.

21. Lintunen, J.; Laturi, J.; Uusivuori, J. How should a forest carbon rent policy be implemented? For. Policy Econ. 2016, 69, 31-39, doi:10.1016/j.forpol.2016.04.005.

22. Kärenlampi P. P. Spruce forest stands at stationary state. J. For. Res. 30(4):1167-1178 (2019). https://doi.org/10.1007/s11676-019-00971-4

23. Speidel, G. Forstliche Betreibswirtschaftslehre, 2nd ed.; Verlag Paul Parey: Hamburg, Germany, 1967, 226p. (In German)

24. Speidel, G. Planung in Forstbetrieb, 2nd ed.; Verlag Paul Parey: Hamburg, Germany, 1972; 270p. (In German)

25. Leslie, A.J. A REVIEW OF THE CONCEPT OF THE NORMAL FOREST. Aust. For. 1966, 30, 139-147, doi:10.1080/00049158.1966.10675407. 
26. $\mathrm{CO} 2$ (metric tons per capita) https://data.worldbank.org/indicator/EN.ATM.CO2E.PC Accessed Jul 11, 2021. 27. http://globalcarbonatlas.org/en/CO2-emissions Accessed Jul 11, 2021.

28. https://www.luke.fi/avoin-tieto/tilastopalvelu/ Accessed Jul 17, 2021.

29. Nurminen, T.; Korpunen, H.; Uusitalo, J. Time consuming analysis of the mechanized cutto-length harvesting system. Silva Fenn. 2006, 40, 335-363.

30. Laiho, O. Metsiköiden alttius tuulituhoille Etelä-Suomessa. Susceptibility of forest stands to wind throw in Southern Finland. Folia For. 706, 1987, 1-24.

31. Gardiner, B.; Schuck, A.; Schelhaas, M.-J.; Orazlo, C.; Blennow, K.; Nicoll, B. (Eds.) Living With Storm Damage to Forests. What Science Can Tell Us European Forest Institute (2013). https://efi.int/sites/default/files/files/publication-bank/2018/efi_wsctu3_2013.pdf Accessed Jul. 19, 2021.

32. Zubizarreta-Gerendiain, A.; Pellikka, P.; Garcia-Gonzalo, J.; Ikonen, V.-P.; Peltola, H. Factors affecting wind and snow damage of individual trees in a small management unit in Finland: assessment based on inventoried damage and mechanistic modelling. Silva Fennica 46(2), 2012, 181-196

33. Pukkala, T.; Laiho, O.; Lähde, E. Continuous cover management reduces wind damage. Forest Ecology and Management 372, 2016, 120-127.

34. Kukkola M; Saramäki J. Growth response in repeatedly fertilized pine and spruce stands on mineral soils. Comm. Inst. For. Fenn. 114, 1983, 55.

35. Pukkala, T. Optimal nitrogen fertilization of boreal conifer forest. For. Ecosyst. 4, 2017, 3. https://doi.org/10.1186/s40663-017-0090-2

36. Bright, R.M.; Strømman, A.H.; Peters, G.P. 2011. Radiative Forcing Impacts of Boreal Forest Biofuels: A Scenario Study for Norway in Light of Albedo. Environmental Science \& Technology 45(17), 2011, 7570-7580.

37. Lukeš, P.; Stenberg, P.; Rautiainen, M. Relationship between Forest Density and Albedo in the Boreal Zone. Ecological Modelling 261, 2013, 74-79.

38. Lutz, D.A.; Howarth, R.B. Valuing Albedo as an Ecosystem Service: Implications for Forest Management. Climatic Change 124, 2014, 53-63.

39. Rautiainen, A.; Lintunen, J.; Uusivuori, J. 2018. Market-Level Implications of Regulating Forest Carbon Storage and Albedo for Climate Change Mitigation. Agricultural and Resource Economics Review 47(2), 2018, 1-33.

40. Rautiainen, A.; Lintunen, J. 2017. Social cost of forcing: A basis for pricing all forcing agents. Ecological Economics 133, 2017, 42-51.

41. Næsset Ramtvedt, E.; Bollandsås, O.M.; Næsset, E.; Gobakken, T. Relationships between single-tree mountain birch summertime albedo and vegetation properties. Agricultural and Forest Meteorology 307, 2021, 108470. https://doi.org/10.1016/j.agrformet.2021.108470.

42. Lintunen, J.; Rautiainen, A.; Uusivuori, J. (2021), Which Is more Important, Carbon or Albedo? Optimizing Harvest Rotations for Timber and Climate Benefits in a Changing Climate. Amer. J. Agr. Econ. 2021. https://doi.org/10.1111/ajae.12219 